\title{
Repair bond strength of aged resin composite using different surface treatments and bonding protocols
}

\author{
Pydiahnaidu Bandaru1,*, Nagesh Bolla², Rupadevi Garlapati³, Sayesh Vemuri², Yamini Bandaru1 \\ ${ }^{1}$ Senior Lecturer, ${ }^{2}$ Professor, ${ }^{3}$ Reader, Department of Conservative Dentistry and Endodontics, Sibar \\ Institute of Dental Sciences, Guntur, Andhra Pradesh, India.
}

\section{N F O R M A T I O}

\section{Article History}

Received $23^{\text {rd }}$ February 2021

Received revised

$12^{\text {th }}$ April 2021

Accepted $16^{\text {th }}$ April 2021

Available online

15 $5^{\text {th }}$ May 2021

\section{K E Y W O R D S}

Resin Composite

Surface treatment

Bonding

Ageing

Thermocycling

Bond strength
Background: Repair of direct composites are less invasive than replacement, diminishing the risk of iatrogenic exposure of the pulp and the risk of detrimental to adjacent teeth, all in all, reducing the procession of the "restoration death spiral".

Aim: This study aimed to evaluate the repair bond strength of aged resin composites using different surface treatments and bonding protocols.

Materials and methods: A total of 45 discs $(n=45)$ were fabricated of Nanohybrid composite measuring about $2.5 \mathrm{~mm}$ in height and $3.5 \mathrm{~mm}$ in diameter and were mounted in acrylic resin and subjected to 10,000 thermal cycles between $5-55^{\circ} \mathrm{C}$ with 30 seconds of dwell time in a thermocycler in order to simulate artificial ageing. All these samples were assigned into three groups $(n=15)$ based on the surface treatment protocol. According to the bonding protocol, the samples in each group are further divided into three subgroups $(n=5)$. After surface treatments of the aged composites, the application of bonding agent followed by new composite material was performed. All the samples were stored in distilled water at $37^{\circ} \mathrm{C}$ for 24 hours. The shear bond strength of the samples was measured using a universal testing machine at a crosshead speed of $1 \mathrm{~mm} / \mathrm{min}$.

Results: Among the groups, the mean bond strength in medium grain diamond bur and 37\% phosphoric acid etchant with the universal bonding agent subgroup was higher $852.56 \pm 27.71$ than the remaining groups. The lowest mean bond strength of $200.9 \pm 10.62$ was observed in $37 \%$ Etchant with direct composite subgroup.

Conclusion: Different combinations of surface treatments and bonding protocols affect shear bond strength differently. The highest shear bond strength values were achieved for the group where surface treatment was done with the combination of blue diamond bur and $37 \%$ phosphoric acid along with a universal bonding agent.

\section{Introduction}

Resin composites are commonly used as direct restorative materials for the esthetic restoration of both anterior and posterior teeth in dental practice [1]. They have critical applications in contemporary restorative dentistry, including but not limited to restorative materials, cavity liners, pit and fissure sealants, core buildup, luting of indirect restorations, provisional restorations, cements for single or multiple tooth prostheses and orthodontic devices, endodontic sealers 
and post bonding [2]. They have considered as the 'material of choice' for use in direct, minimal intervention approaches with adhesive techniques due to their aesthetic and physical properties $[3,4]$.

Composites present various advantages, such as ease of handling, satisfactory physical and mechanical properties and the most excellent esthetic appearance [5]. They also have several disadvantages like secondary caries, marginal staining, marginal defects, marginal or body fracture, discoloration, degradation and loss of anatomical form, unsatisfactory shade, and painful symptoms [6].

Although composite materials are adhesively bonded to the tooth structure, they are subjected to different degenerative changes [7]. The degradation of resin composites is complex and includes intraoral degradation (mechanical, physical, or chemical) and extraoral degradation (storage and shelf life of the material) [8]. Composites are less stable in fluids and have a higher degradation rate in saliva simulating conditions. The enzymes present in the saliva of the oral cavity degrade the composite matrix. All these factors affect the clinical longevity and success of composite restorations $[9,10]$.

Therefore, to effectively improve the longevity of composite restorations, they need to be either refurbished, repaired or replaced [11]. Refurbishment refers to the addition of restorative material without removing material or dental structure [12]. Repair refers to removing defective parts and adding new composite resin to remaining aged resin composite restorations and/or adjacent tissues, leaving the intact part in place [13]. Replacement refers to the complete removal of restorative material for the placement of new material [14].

Replacement was used to treat defective composite restorations traditionally. But repairing serviceable composite restorations have gained wider acceptance regarding the modern concept of minimally invasive dentistry [15].

The success of the repair is dependent on the magnitude of the bond strength obtained at the interface of old and new restoration [16]. The bonding and shear bond strength are improved due to the presence of Camphoroquinone in the new composite layer, which is essential for complete polymerization of the oxygen inhibited layer at the inter-phase [17]. Therefore, adequate surface treatment of the old resin, section of an adhesive system, and the appropriate restorative material are required to repair an existing restoration successfully $[18,19]$.

Numerous surface treatments promote mechanical interlocking, surface wetting, and chemical bonding during composite repair [12]. The surface treatments include surface roughening with diamond burs [20], silicon papers, carborundum stones [21], finishing discs [22], sandblasting [21,23], airborne particle abrasion with aluminium oxide particles with or without silanated silica coating [24], acid etching with phosphoric or hydrofluoric acid [25], silane coupling agent application [22,26], and resin-based adhesive systems application.

These surface treatments and bonding protocols showed variable results on the composite repair bond strength. Therefore, this study was designed to evaluate composite restorations' repair bond strength through different surface treatments and bonding protocols. The null hypothesis was that there were no differences between the bond strength values of repairs performed on composites, and the surface treatment protocols applied have no influence on these repairs' bond strength.

\section{Materials and methods}

The armamentarium of the present study was presented in Figure 1. In this in vitro study, 45 discs $(n=45)$ were fabricated of composite (Herculite Ultra, Kerr, United States) measuring about $2.5 \mathrm{~mm}$ in height and $3.5 \mathrm{~mm}$ in diameter. All the samples were mounted in acrylic resin. they were subjected to 10,000 thermal cycles between $5-55^{\circ} \mathrm{C}$ with 30 seconds of dwell time in a thermocycler (Model TS130, Weiss Umwelttechnik Gmbh, Germany) in order to simulate artificial ageing.

The samples were assigned into three groups based on the surface treatment protocol, with fifteen samples $(n=15)$ (Figure 2) in each group. In Group I, the samples $(n=15)$ were surface treated with the application of $37 \%$ phosphoric acid (d-tech, India) for 20 seconds (Figure 3). In Group II, the samples $(n=15)$ were surface treated with the use of medium grain diamond bur driven in a high-speed airrotor handpiece (NSK, Japan) (Figure 4). In Group III, the samples $(n=15)$ were surface treated with the combination of medium 
grain diamond bur driven in a high-speed airrotor handpiece (NSK) followed by the application of $37 \%$ phosphoric acid (d-tech, India) for 20 seconds.

The samples $(\mathrm{n}=15)$ of each group were further divided into three subgroups with five specimens in each $(n=5)$ for repairing. In the group I, all the three subgroups were treated with $37 \%$ phosphoric acid (d-tech). Then, the first subgroup was restored with direct composite (Beautifil-II composite, SHOFU Dental ASIA-Pacific P. Ltd., Singapore) with a Teflon coated composite instrument and light-cured for 30 seconds. The second subgroup specimens were applied with a universal bonding agent for 10 seconds with an applicator tip. The specimens in the third subgroup were restored with flowable composite (Flow plus composite, SHOFU Dental ASIA-Pacific P. Ltd, Singapore) and light-cured for 30 seconds.

In the group II, all the three subgroups were surface treated with medium grain diamond bur driven in a high-speed airrotor handpiece (NSK Japan). Then the specimens were restored with direct composite and a universal bonding agent and flowable composite as disrobed in the group I. In group III, all the specimens in the subgroups were surface treated with medium grain diamond bur drivenin a high-speed airrotor handpiece (NSK), followed by treating with $37 \%$ phosphoric acid (d-tech). Then, the specimens were restored as described in the group I and II.

Various surface treatments of the aged composite were performed prior to the application of the bonding agent and then followed by the addition of new composite material. All the samples were stored in distilled water at $37^{\circ} \mathrm{C}$ for 24 hours. Shear bond testing for the samples was measured using a universal testing machine (Instron, UK) at a crosshead speed of $1 \mathrm{~mm} /$ minute. Statistical analysis was done by using Kruskal-Wallis and Analysis of Variance (ANOVA) tests.

\section{Results}

Results of Kruskal-Wallis and Analysis of Variance tests showed a statistically significant difference between the groups. Mean shear bond strength $(\mathrm{kN} / \mathrm{m} 2)$ and standard deviation of all the combinations of surface treatment and bonding protocol and flowable composite application were presented in table 1 . The highest shear bond strength values were observed in Group III (surface treatment with medium grain blue diamond bur and $37 \%$ phosphoric acid) (Table 1 and figure 5).

In the subgroups, placement of new composite material over the aged composite in situ with the application of bonding agent showed higher shear bond strength values than other subgroups (Table 1 and figure 5). The least mean shear bond strength was observed in the direct composite specimens etched with 37\% etchant. Significant differences in the shear bond strength were observed among the groups (Table 1).

\section{Discussion}

Composite resins are tooth-coloured materials commonly used for aesthetic restorations of anterior and posterior teeth. Composites are polymer matrix filled materials, which derives their physical properties and handling characteristics from loading with reinforcing filler particles and the viscosity of the resin matrix [27-29]. They need the application of adhesive systems for adequate bonding and sealing of the restorations [30]. The primary aim of dental adhesives is to provide retention to composite restorations, withstand mechanical forces and prevent leakage along the restorative margins [31]. Bonding to the enamel can be achieved effectively due to its uniform composition of hydroxyapatite. In contrast, adhesion to dentin has several challenges due to the presence of water, smear layer, smear plugs and heterogeneous nature $[32,33]$.

Table 1. Shear bond strength in $\mathrm{kN} / \mathrm{m} 2$ (Mean \pm standard deviation) of all combinations of surface treatments and restored with direct composite, bonding agent and flowable composite.

\begin{tabular}{lcccc}
\hline \multicolumn{1}{c}{ Groups } & $\mathbf{3 7 \%}$ Etchant & $\begin{array}{c}\text { Medium grain } \\
\text { diamond bur }\end{array}$ & $\begin{array}{c}\text { Medium grain diamond bur } \\
\text { and 37\% Etchant }\end{array}$ & $\begin{array}{c}\text { Significance } \\
\text { (p-Value) }\end{array}$ \\
\hline $\begin{array}{l}\text { Direct Composite } \\
\text { Universal Bonding }\end{array}$ & $200.9 \pm 10.62$ & $368.84 \pm 46.4$ & $417.12 \pm 38.77$ & 0.004 \\
$\begin{array}{l}\text { Agent } \\
\text { Flowable }\end{array}$ & $400.82 \pm 70.4$ & $576.52 \pm 105.4$ & $852.56 \pm 27.71$ & 0.002 \\
$\begin{array}{l}\text { Composite } \\
\begin{array}{l}\text { Significance } \\
\text { (p-Value) }\end{array}\end{array}$ & $524.3 \pm 28.4$ & $557.8 \pm 28.4$ & $660.4 \pm 34.3$ & 0.008 \\
\hline
\end{tabular}



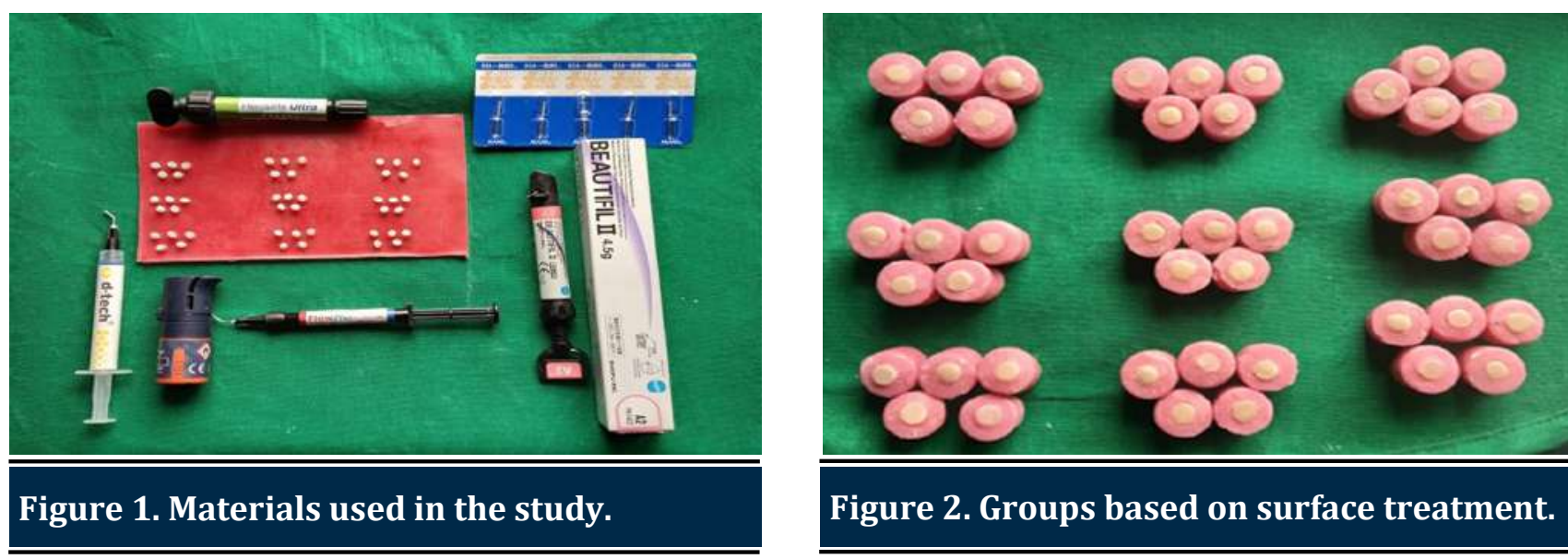

Figure 2. Groups based on surface treatment.
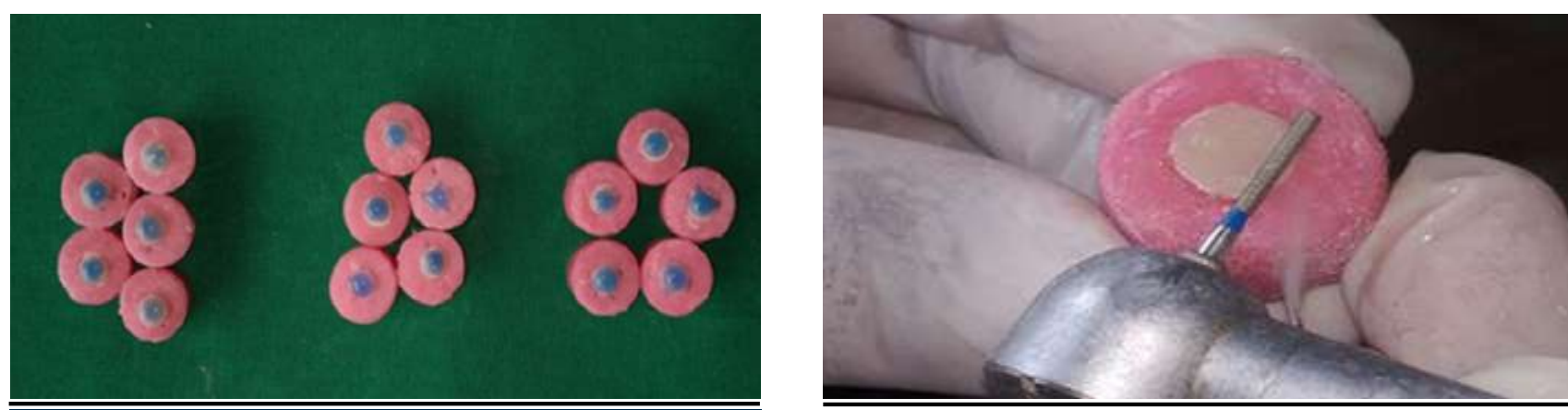

Figure 3. Surface treatment with $\mathbf{3 7 \%}$ phosphoric acid.

Figure 4. Surface treatment with medium grain diamond bur.

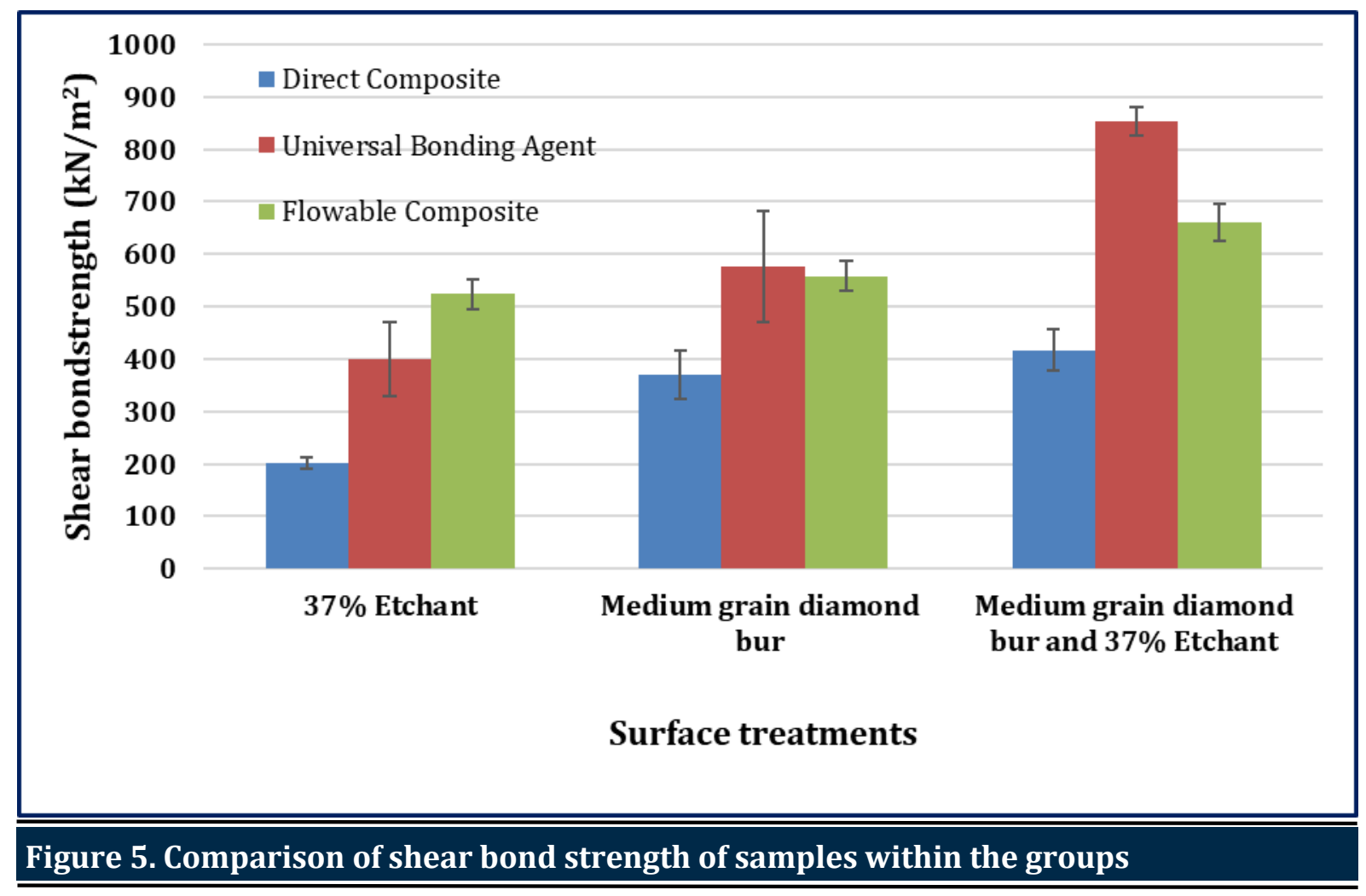


Composite restorations are prone to ageing or failure in the long term. Artificial ageing of composite resins can be done through thermal cycling, boiling, and storage of the dry material at $37^{\circ} \mathrm{C}$ in acids, immersion in water, sodium chloride, artificial saliva or hot water [34-36]. In the present study, thermocycling of the samples was done to simulate hydrothermal ageing. Thermal temperatures between $5^{\circ} \mathrm{C}$ and $55^{\circ} \mathrm{C}$ coupled with water contributed to ageing in this study.

Repairing of aged composite restoration was considered as the treatment of choice rather than replacement [37]. Since the repair process results in weaker restorations, successful repair requires the development of an adequate interfacial bond between aged and new resin composites [23]. Repair bond strength can be influenced by several factors such as organic matrix composition, filler load, filler size, surface treatment for repair, conditioning prior bonding, application of silane coupling agent and adhesive system $[13,38]$.

The interface between aged and new composite is the weakest link of the restoration [39]. Therefore, several ways have been proposed to improve the interfacial bond between aged and new composite, including surface treatments, either physical or chemical, to improve mechanical keying and chemical coupling at the adhesive interface $[20,25,40]$. In the present study, surface treatments were carried out using $37 \%$ phosphoric acid, medium grain diamond bur and a combination of both for the samples, respectively.

The phosphoric acid acts by the infiltration of resin monomers into the microporosities created by the dissolution of enamel and subsequent dissociation of the exposed hydroxyapatite crystals with polymerized monomers within the pores on the enamel surface, thereby accomplishing micromechanical retention [41]. Surface treatment with diamond bur resulted in creating macro irregularities. The conditioning of the aged composite surface aimed to obtain a cleansing effect, removal of debris and particles that have remained after treatment [42].

The present study showed the highest shear bond strength among the samples treated with medium grain diamond bur and 37\% phosphoric acid (Table 1). This can be supported by the fact that prior surface treatment with diamond bur removed the superficial layer of the old composite. Later etching resulted in more penetration of composite into the microporosities, thus, enhancing the shear bond strength. The results of this study were consistent with the study done by Eliguzeloglu E et al. (2008) [43] reported that high surface roughness created with bur might have increased the dentin surface, promoting for better contact between the dental substrate and adhesive [43].

Lower shear bond strength values were observed in samples treated with $37 \%$ phosphoric acid and diamond bur, respectively (Table 1). Lower shear bond strength values with the treatment of $37 \%$ phosphoric acid were due to the collapse of resin matrix of composite in situ, creating improper bonding, which was in accordance with the study done by Sabatini C. (2013) [44] stated that surface treatment with acid etching might lead to incomplete adhesive infiltration into the denuded collagen network and also residual hydroxyapatites removal from collagen mesh due to sub-optimal removal of the phosphoric acid all together compromises the potential for chemical adhesion.

The results of the present study also presented higher shear bond strength values in subgroups characterized by the placement of new composite material over the old composite with the application of universal bonding agent, i.e., water/ethanol-based and both selfetch one-step adhesives when compared to other subgroups (Table 1), that was in accordance with the study done by Eliasson ST et al. (2017) [45] stated that the Scotchbond Universal promotes adhesion as it contains small amounts of silane or increases wettability as a coupling agent, thus enhancing bond strength.

Long-term water storage affects the mechanical properties of composite materials. For this reason, the samples in the present study were stored in distilled water only for 24 hours that was in accordance with study b Ferracane JL et al. (1998) [46] stated that water storage shows less significant effect on mechanical properties and indicates limited decomposition of composites in water.

In the present study, shear bond strength testing was done using a universal testing machine consisting of a notched cross-head designed to match the bonded specimen's diameter and apply a specific testing load in concurrence with the study done by Sabatini C. (2013) [44]. 


\section{Conclusion}

Different combinations of surface treatments and bonding protocols affect shear bond strength differently. The highest shear bond strength values were achieved for the group where surface treatment was done with the combination of blue diamond bur and $37 \%$ phosphoric acid along with a universal bonding agent. In contrast, the lowest values were observed with $37 \%$ phosphoric acid as the surface treatment agent and placement of direct composite.

Conflicts of interest: Authors declared no conflicts of interest.

\section{Financial support: None}

\section{References}

1. Leevailoj C, Ua-wutthikrerk P, Poolthong S. Shear bond strength of dual-cured and self-cured resin composites to dentin using different bonding agents and techniques. Oper Dent 2007;32(2):149-159. https:// doi.org/10.2341/06-41

2. Ferracane JL. Resin composite- State of the art. Dent Mater 2011;27(1):29-38.

https://doi.org/10.1016/j.dental.2010.10.020

3. Lynch CD, Opdam NJ, Hickel R, Brunton PA, Gurgan S, Kakaboura A, Shearer AC, Vanherlr G, Wilson NHF. Guidance on posterior resin composites: Academy of Operative Dentistry- European Section. J Dent 2014;42(4):377-383.

https://doi.org/10.1016/j.jdent.2014.01.009

4. Ruchi Gupta, Anil K Tomer, Anamika Kumari. In vitro evaluation of marginal sealing ability of Bulk fill Flowable composite resins. IOSR J Dent Med Sci 2017;16(1):10-13.

https://doi.org/10.9790/0853-1601111013

5. Lee SK, Kim TW, Son SA, Park JK, Kim JH, Kim $\mathrm{HI}$, et al. Influence of light-curing units on the polymerization of low-shrinkage composite resins. Dent Mater J 2013;32(5):688-694.

https://doi.org/10.4012/dmj.2013-027

6. Parpaiola AR, Guimaraes PS, Franca FM, Basting RT. Small cross-sectional survey of composite restoration attributes associated with choices for replacement. Braz Oral Res. 2009;23(3):346-351. https:// doi.org/10.1590/S1806-83242009000300020

7. Hasan M, Khan FR, Rahman M. Teaching and practice of repair of resin composite restorations in dental institutions of Karachi. J Pak Dent Assoc. 2011;20 (4):216-221.

8. Ferracane JL. Hygroscopic and hydrolytic effects in dental polymer networks. Dent Mater. 2006;22 (3):211-222. https://doi.org/10.1016/j.dental.2005.05.005
9. Musanje L, Darvel BW. Aspects of water sorption from the air, water and artificial saliva in resin composite restorative materials. Dent Mater. 2003;19 (5):414-422. https://doi.org/10.1016/S0109-5641(02) 00085-4

10. Soderholm KJ, Mukherjee R, Longmate J. Filler leachabiity of composites stored in distilled water or artificial saliva. J Dent Res. 1996;75(9):1692-1699. https://doi.org/10.1177/00220345960750091201

11. Major IA, Moorhead JE, Dahl JE. Reasons for replacement of restorations in permanent teeth in general dental practice. Int Dent J. 2000;50(1):361-366. https://doi.org/10.1111/j.1875-595X.2000.tb00569.x

12. Valente LL, Onofre RS, Goncalves AP, Fernandez E, Loomans B, Moraes RR. Repair bond strength of dental composites: Systematic review and metaanalysis. Int J Adhes \& Adhesives. 2016;1(1):01-26. https://doi.org/10.1016/j.ijadhadh.2016.03.020

13. Hickel R, Peschke A, Tyas M, et al. FDI word dental federation: clinical criteria for the evaluation of direct and indirect restorations- update and clinical examples. Clin Oral Invest. 2010;14(2):349-366. https:// doi.org/10.1007/s00784-010-0432-8

14. Brendeke J, Ozcan M. Effect of physicochemical aging conditions on the composite-composite repair bond strength. J Adhes Dent 2007;9(3):399-406.

15. Sharif MO, Cateugh M, Merry A, Tickle M, Dunne $\mathrm{SM}$, et al. Replacement versus repair of defective restorations in adults: resin composite. The Cochrane Collaboration John Wiley \& Sons Ltd 2010;2(1):0113.https://doi.org/10.1002/14651858.CD005971.pub2

16. Lewis G, Johnson W, Martin W, Canerdy A, Claburn C, Collier M. Shear bond strength of immediately repaired light-cured composite resin restorations. Oper Dent. 1998;23(3):121-127.

17. Jagadish SM. The role of oxygen inhibited layer on the shear bond strength of composites: an in vitro evaluation. J Conserv Dent. 2007;10(1):01-04. https://doi.org/10.4103/0972-0707.42273

18. Cakir NN, Demirbuga S, Balkaya H, et al. Bonding performance of universal adhesives on composite repairs, with or without silane application. J Conserv Dent. 2018;21(2):263-268. https://doi.org/10.4103/JCD.JCD_11_18

19. Ritter AV, Sulaiman TA, Altitinchi A, Bair E, Filho FB, Gonzaga CC, Correr GM. Composite-composite adhesion as a function of adhesive-composite material and surface treatment. Oper Dent. 2019;44(4):348354. https://doi.org/10.2341/18-037-L

20. Papacchini F, DalOca S, Chieffi N, Goracci C, Sadek FT, Suh BI, et al. Composite-to-composite microtensile bond strength in the repair of a microfiled hybrid resin: Effect of surface treatment and oxygen inhibition. J Adhes Dent. 2007;9(4):25-31.

21. Brosh T, Pilo R, Bichacho N, Blutstein R. Effect of combinations of surface treatments and bonding agents on the bond strength of repaired composites. 
J Prosthet Dent. 1997;77(2):122-126. https:// doi.org/10.1016/S0022-3913(97)70224-5

22. Furuse AY, da Cunha LF, Benetti AR, Mondelli J. Bond strength of resin-resin interfaces contaminated with saliva and submitted to different surface treatments. J Appl Oral Sci. 2007;15(6):501-505. https:// doi.org/10.1590/S1678-77572007000600009

23. Cavalcanti AN, De Lima AF, Peris AR, Mitsui FH, Marchi GM. Effect of surface treatments and bonding agents on the bond strength of repaired composites. J Esthet Restor Dent. 2007;19(2):90-98. https:// doi.org/10.1111/j.1708-8240.2007.00073.x

24. Bouschlicher MR, Reinhardt JW, Vargas MA. Surface treatment techniques for resin composite repair. Am J Dent. 1997;10(6):279-283.

25. Jr Rodrigues SA, Ferracane JL, Della Bona A. Influence of surface treatments on the bond strength of repaired resin composite restorative materials. Dent Mater. 2009;25(4):442-451. https://doi.org/10.1016/i.dental.2008.09.009

26. Shahdad SA, Kennedy JG. Bond strength of repaired anterior composite resins: an in vitro study. J Dent 1998;26(8):685-694. https://doi.org/10.1016/S0300-5712(97)00044-4

27. Saraswathi MV, Jacob G, Ballal NV. Evaluation of the influence of flowable liner and two different adhesive systems on the microleakage of packable composite resin. J Interdisciplinary Dent 2012;2(2):98103. https://doi.org/10.4103/2229-5194.100601

28. Ravi RK, Alla RK, Shammas M, Devarhubli A. Dental Composites-A Versatile Restorative Material: An Overview. Indian Journal of Dental Sciences. 2013;5 (5):111-15.

29. Dara L, Buchi D, Mantena SR, Varma M, Chandrappa V. Recent Advances in Dental Composites: An Overview. Int J Dent Mater. 2019;1(2):48-54. https:// doi.org/10.37983/IJDM.2019.1202

30. Shafiei F, Saadat M. Micromorphology and bond strength evaluation of adhesive interface of a selfadhering flowable composite resin-dentin: effect of surface treatment. Microsc Res Tech. 2016;79(5):403 -407. https://doi.org/10.1002/jemt.22643

31. Van Landuyt KL, Snauwaert J, De Munck J, Peumans M, Yoshida Y, Poitevin A, et al. Systematic review of the chemical composition of contemporary dental adhesives. Biomater. 2007;28(26):3757-3785. https://doi.org/10.1016/j.biomaterials.2007.04.044

32. Montes MA, de Goes MF, Sinhoreti MA. The in vitro morphological effects of some current pretreatments on dentin surface: A SEM evaluation. Oper Dent. 2005;30(5):201-212.

33. Kadali NS, Alla RK, Guduri V, Sajjan S. An overview of dentin bonding agents. Int $\mathrm{J}$ Dent Mater. 2019;1(2):60-7.

https://doi.org/10.37983/IJDM.2019.1204

34. Bonstein T, Garlapo D, Jr Donarummo J, Bush PJ. Evaluation of varied repair protocols applied to aged composite resin. J Adhes Dent. 2005;7(1):41-49.

35. Ozel BO, Eren D, Herguner SS, Akin GE. Effect of thermocycling on the bond strength of composite resin to bur and laser treated composite resin. Lasers Med Sci. 2012;27(3):723-728.

https://doi.org/10.1007/s10103-011-0958-2

36. Ozcan M, Cura C, Brendeke J. Effect of aging conditions on the repair bond strength of a microhybrid and a nanohybrid resin composite. J Adhes Dent. 2010;12 (4):451-459.

37. Strassler HE. Clinical decision-making for restoration replacement or repair. Inside Dentistry. 2012;2(2):0206.

38. Rathke A, Tymina Y, Haller B. Effect of different surface treatments on the composite-composite repair bond strength. Clin Oral Invest 2009;13(2):317-323. https://doi.org/10.1007/s00784-008-0228-2

39. Lucena-Martin C, Gonzalez-Lopez S, NavajasRodriguez de Mondela JM. The effect of various surface treatments and bonding agents on the repaired strength of heat-treated composites. J Prosthet Dent. 2001;86(2):481-488.

https://doi.org/10.1067/mpr.2001.116775

40. Teixeira EC, Bayne SC, Thompson JY, Ritter AV, Swift EJ. Shear bond strength of self-etching bonding systems in combination with various composites used for repairing aged composites. J Adhes Dent. 2005;7 (2):159-164.

41. Swift EJ, Perdigao J, Heymann HO. Bonding to enamel and dentin: a brief story and state of the art. Quintessence Int. 1995;26(2):95-110

42. Balkenhol M, Michel K, Stelzig J, Wostmann B. Repairability of cross-linked biopolymers. J Dent Res. 2009;88(3):152-157.

https://doi.org/10.1177/0022034508329703

43. Eliguzeloglu E, Omurlu H, Eskitascioglu G, Belli S. Effect of surface treatments and different adhesives on the hybrid layer thickness of non-carious cervical lesions. Operative dentistry. 2008;33(3):338-45. https://doi.org/10.2341/07-96

44. Sabatini C. Effect of phosphoric acid etching on the shear bond strength of two self-etch adhesives. J Appl Oral Sci. 2013;21(1):56-62.

https://doi.org/10.1590/1678-7757201302370

45. Eliasson ST, Dahl JE. Effect of curing and silanizing on composite repair bond strength using an improved micro-tensile test method. Acta biomaterialia odontologica Scandinavica. 2017;3(1):21-9. https://doi.org/10.1080/23337931.2017.1301211

46. Ferracane JL, Berge HX, Condon JR. In vitro aging of dental composite in water-effect of degree of conversion, filer volume, and filer/matrix coupling. J Biomed Mater Res 1998;42(1):465-472. https:// doi.org/10.1002/(SICI)1097-4636(19981205) 42:3<465::AID-JBM17>3.0.CO;2-F 